\title{
ENSAIOS TOXICOLÓGICOS COM SEMENTES PARA AVALIAÇÃO DE TRATAMENTO DO CHORUME POR FILTRAÇÃO LENTA E FOTOCATÁLISE
}

\author{
TOXICOLOGICAL TESTS WITH SEEDS FOR \\ LEACHATE TREATMENT EVALUATION BY SLOW \\ FILTRATION AND PHOTOCATALYSIS
}

\section{Núbia Natália Brito ${ }^{1}$, Giovani Archanjo Brota ${ }^{2}$, Eloisa Maria dos Santos ${ }^{3}$, Noely Bochi Silva ${ }^{3}$, Ronaldo Teixeira Pelegrini ${ }^{4}$, José Euclides Stipp Paterniani ${ }^{5}$}

${ }^{1}$ Química Agro-Industrial, Profa. Dra. Instituto de Química IQ. Universidade Federal de Goiás (UFG). e-mail: nubiabrito@quimica.ufg.br

${ }^{2}$ Tecnólogo em Saneamento. Faculdade de Engenharia Agrícola FEAGRI.

Universidade Estadual de Campinas (UNICAMP).

${ }^{3}$ Tecnóloga em Saneamento. Centro Superior de Educação Tecnológica CESET.

Universidade Estadual de Campinas (UNICAMP).

${ }^{4}$ Licenciado em Química. Prof. Dr. Centro de Ciências Agrárias CCA- Universidade Federal de São Carlos (UFSCAR)

${ }^{5}$ Engenheiro Civil. Prof. Dr. Faculdade de Engenharia Agrícola FEAGRI.

Universidade Estadual de Campinas (UNICAMP).

\section{RESUMO}

Este trabalho teve como objetivo estudar as técnicas de Filtração Lenta seguida de Fotocatálise heterogênea $\left(\mathrm{TiO}_{2} / \mathrm{UV}\right)$ no tratamento de chorume proveniente do aterro sanitário da cidade de Limeira-SP. Foram empregados ensaios toxicológicos utilizando sementes de Abelmoschus esculentus L. (Quiabo); Lactuca sativa L. (Alface); Impatiens balsamina (Balsamina) e Celosia cristata (Crista-de-galo), para avaliar a eficiência do tratamento. Os ensaios toxicológicos demonstraram a possibilidade de utilização de maior concentração do chorume tratado na germinação das sementes, sendo que foi possível adicionar $96 \%$ de chorume para a germinação das sementes de quiabo, $30 \%$ para a alface, $54 \%$ para a dobrada sortida e $40 \%$ para germinação das sementes de flores crista de galo. Também foram observadas reduções dos valores de parâmetros de grande importância ambiental, tais como, coloração que apresentou reduções em torno de 76,42\%, Carbono Orgânico Total (COT) $67,88 \%$, fenóis totais $77,13 \%$ e nitrogênio amoniacal $34,63 \%$. A metodologia 
de tratamento empregando Filtração Lenta e Fotocatálise demonstrou ser uma excelente opção de remediação de chorume.

Palavras-chave: Chorume. Aterro sanitário. Fotocatálise. Toxicidade. Tratamento.

\begin{abstract}
This work had as objective to study the techniques of Slow Filtration followed by heterogeneous photocatalysis $\left(\mathrm{TiO}_{2} / \mathrm{UV}\right)$ in the leachate' treatment originating from the sanitary landfill of Limeira-SP, City. Toxicological testes were used with seeds of Abelmoschus esculentus L.; Lactuca sativa L.; Impatiens balsamina and Celosia cristata to evaluate the treatment efficiency. The toxicological testes demonstrated the possibility of use larger concentration of leachate treated in the seeds germination, and it was possible to add $96 \%$ of leachate for the Abelmoschus esculentus $L$ seeds germination, $30 \%$ for the Lactuca sativa $L, 54 \%$ for Impatiens balsamina and $40 \%$ for Celosia cristata. Also were observed parameter values reductions of the environmental importance great, such as, coloration that presented reductions approximated $76,42 \%$, total organic carbon (TOC) $67,88 \%$, total phenols $77,13 \%$ and amoniacal nitrogen $34,63 \%$. The treatment methodology using Slow Filtration and Photocataysis demonstrated to be an excellent option of leachate remediation.
\end{abstract}

Keywords: Leachate. Sanitary landfill. Photocatalysis. Toxicity. Treatment.

\title{
1. INTRODUÇÃO
}

O chorume é um líquido gerado nos aterros sanitários e geralmente apresenta um forte mau cheiro, coloração muito intensa sendo também muito tóxico. Pode conter altas concentrações de compostos orgânicos, metais tóxicos, amônia, cloretos e muitos outros compostos solúveis. Sua composição físico-química é extremamente variável dependendo de diversos fatores que vão desde as condições pluviométricas, tempo de disposição, idade do aterro, condições ambientais e características do próprio despejo (BRITO et al., 2007).

Devido à grande diversidade de poluentes presentes no chorume pode ser esperado um efeito sinérgico de interação entre os compostos que multiplica várias vezes seu efeito tóxico. A falta de controle e tratamento adequados do chorume pode provocar a contaminação do solo, do ar e das águas superficiais e subterrâneas, além de propiciar a proliferação de vetores de doenças, em detrimento da qualidade do meio ambiente e da saúde pública (CELERE et al., 2007). Um exemplo disso é que, segundo Aluko e Sridhar (2005), na Nigéria o chorume tem causado doenças em produtores rurais por meio do desenvolvimento de anomalias, baixo peso no nascimento de crianças, incidências de leucemia e outros tipos de câncer. O chorume 
também tem causado distúrbios na reprodução de peixes em lagos na Suécia, onde após tratamento biológico é descartado em afluentes (DAVE e NILSSON, 2005).

As técnicas de tratamento do chorume são as comumente empregadas no tratamento de efluentes industriais, incluindo os tradicionais processos aeróbios e anaeróbios. Esses métodos, no entanto, são insuficientes para garantir degradação adequada das principais classes de poluentes e o chorume tem sido descartado apresentando ainda forte coloração e alta toxicidade, constituindo graves problemas para os corpos receptores.

O desenvolvimento de técnicas alternativas que podem degradar compostos tóxicos presentes no chorume, juntamente com métodos adequados de controle, tem tornado cada vez mais urgentes.

\section{A Filtração Lenta}

Estudos recentes têm demonstrado que o sistema de filtração lenta pode ser usado para tratamento de águas residuárias, apresentando alta eficiência na redução da matéria orgânica e derivados do nitrogênio (CAMPOS et al., 2002; MERMILLOD-BLONDIN et al., 2005), reduções de espécies orgânicas tóxicas (CHEN e LU, 2004) e reduções de metais pesados de alto impacto ambiental como cádmio, cromo e chumbo (MUHAMMAD e HOOKE, 2003).

No sistema de filtração lenta existe a formação de uma camada biológica no topo do meio filtrante denominada de Schmutzdecke constituída fundamentalmente de partículas inertes, matéria orgânica e uma grande variedade de microrganismos, tais como bactérias, algas, protozoários e outros (DI BERNARDO 1993). Essa camada biológica contribui significativamente para degradação de diversos compostos poluentes, sendo que a atividade biológica é uma das características importantes do filtro lento para o tratamento de águas residuárias, funcionando como um reator aeróbio e anaeróbio simultaneamente (ADIN 2003).

A taxa de filtração nos filtros lentos é limitada pela NBR 592 de 1989 (DI BERNARDO 1999) em $6 \mathrm{~m}^{3} / \mathrm{m}^{2}$.d quando se tem meio filtrante constituído unicamente de areia. Embora as pesquisas realizadas com mantas sintéticas indiquem a possibilidade da utilização de taxa de filtração dessa ordem de grandeza, têm sido recomendados valores da taxa de filtração entre 2 e $5 \mathrm{~m}^{3} / \mathrm{m}^{2}$.d, dependendo da qualidade do afluente e da carga hidráulica disponível total (BRITO, 2006).

\section{Fotocatálise Heterogênea}

A Fotocatálise Heterogênea é uma técnica capaz de gerar uma espécie química denominada de radical hidroxila $\left({ }^{\circ} \mathrm{OH}\right)$. Este radical é um agente oxidante com alta capacidade de degradar diversas classes de poluentes orgânicos devido ao seu elevado potencial de oxidação $\left(\mathrm{E}^{\mathrm{o}}=+2,8 \mathrm{~V}\right)$, podendo reagir com quase todo tipo de substância, subtraindo dela elétrons ou átomos de hidrogênio ou ainda adicionando-se às duplas ligações, tornando esta metodologia de grande interesse para uso em 
recuperação de ambientes quimicamente degradados (NOGUEIRA e JARDIM, 1998).

$\mathrm{O} \mathrm{TiO}_{2}$ é o semicondutor mais utilizado na Fotocatálise Heterogênea devido às várias propriedades interessantes tais como: possibilidade de ativação por luz apresenta insolubilidade em água, estabilidade química numa ampla faixa de $\mathrm{pH}$, possibilidade de imobilização em sólidos, baixo custo, possibilidade de reutilização e ausência de toxicidade (NOGUEIRA e JARDIM, 1998).

$\mathrm{O}$ processo da excitação fotocatalítica do $\mathrm{TiO}_{2}$ demanda uma fonte luminosa (geralmente UV) e presença de oxigênio que é usado para retirar os elétrons do semicondutor foto-sensibilizado e favorecer a geração do radical hidroxila (Eq. 1) (ZIOLLI e JARDIM, 1998).

$$
\mathrm{TiO}_{2}+\mathrm{H}_{2} \mathrm{O}+\mathrm{O}_{2}+\mathrm{UV} \rightarrow \mathrm{OH}+\mathrm{O}_{2}^{--}+\mathrm{H}^{+}+\mathrm{TiO}_{2}
$$

\section{Estudos Toxicológicos Utilizando Sementes}

No processo de germinação das sementes, a água representa um dos fatores do ambiente que mais exerce influencia. Com a absorção de água ocorre a re-hidratação dos tecidos e, consequentemente, a intensificação da respiração e de todas as outras atividades metabólicas, que resultam com o fornecimento de energia e nutrientes necessários para a retomada de crescimento por parte do eixo embrionário (NASSIF et al., 1998).

Uma maneira simples e rápida para avaliar se o efluente tratado diminuiu seu potencial tóxico é através de estudos toxicológicos utilizando sementes, mediante avaliação do processo de germinação. A germinação depende de uma seqüência de eventos fisiológicos influenciada por fatores externos (ambientais) e internos (dormência, inibidores) (NASSIF et al., 1998).

Desta forma as sementes tornam-se bem apropriadas para ensaios toxicológicos realizados em espaços que não exigem técnicas e equipamentos sofisticados, nem ambientes extremamente controlados, tornando-se uma metodologia importante para popularização dos ensaios toxicológicos ou para avaliação da qualidade do tratamento de águas residuárias que se pretende utilizar em atividades agrícolas.

Neste trabalho, estudou-se uma combinação de duas técnicas de tratamento: a filtração lenta com seqüencial fotocatálise com $\mathrm{TiO}_{2}$ e para avaliar a eficiência dessas metodologias foram estudadas prioritariamente ensaios toxicológicos com sementes.

Foi avaliado o potencial de germinação de algumas sementes frente às diversas diluições de chorume a fim de verificar a diminuição da toxicidade crônica deste agente estressor, após os tratamentos por filtração lenta e fotocatálise heterogênea. 


\section{MATERIAL E METODOS}

Amostras de chorume foram obtidas de um aterro sanitário municipal com mais de 14 anos de idade, localizado em Limeira (São Paulo, Brasil). Este aterro recebe resíduos sólidos municipais e resíduos industriais classe I e IIA e IIB. As amostras foram coletadas em garrafas de polipropileno e mantidas a $4{ }^{\circ} \mathrm{C}$, protegidas da luz. Algumas características físico-químicas do chorume estão apresentadas na Tabela 1.

O semicondutor utilizado no processo fotocatalítico heterogêneo Dióxido de Titânio - Degussa P25 $\left(\mathrm{TiO}_{2}\right)$ foi adquirido da indústria Degussa S.A. na cidade de São Paulo.

Tabela 1 - Caracterização físico-química do chorume do aterro sanitário de Limeira-SP

\begin{tabular}{|c|c|}
\hline Parâmetros & Chorume in natura \\
\hline Nitrogênio $\mathrm{NH}_{4}{ }^{+}\left(\mathrm{mg} . \mathrm{L}^{-1}\right)$ & 446,67 \\
\hline Nitrito $\mathrm{NO}_{2}^{-}\left(\mathrm{mg} \cdot \mathrm{L}^{-1}\right)$ & 0,22 \\
\hline Nitrato $\mathrm{NO}_{3}^{-}\left(\mathrm{mg} \cdot \mathrm{L}^{-1}\right)$ & 2,66 \\
\hline Cloretos (mg.L $\mathrm{L}^{-1}$ ) & 1825 \\
\hline Ferro $\left(\mathrm{mg} \cdot \mathrm{L}^{-1}\right)$ & 54,16 \\
\hline $\mathrm{pH}$ & 8,01 \\
\hline Cor (Abs $400 \mathrm{~nm})$ & 2,460 \\
\hline Turbidez UNT & 68,7 \\
\hline Condutividade $\left(\mathrm{mS} \mathrm{cm}^{-1}\right)$ & 12,21 \\
\hline Fenóis Totais (mg.L $\left.\mathrm{L}^{-1}\right)$ & 24,09 \\
\hline COT (mg.L $\left.\mathrm{L}^{-1}\right)$ & 3029,54 \\
\hline $\mathrm{AOX}\left(\mathrm{mg} \cdot \mathrm{L}^{-1}\right)$ & 0,905 \\
\hline
\end{tabular}

Fonte: (BRITO, 2006).

\section{Pré-tratamento por Filtração Lenta}

O chorume in natura foi pré-tratado em um filtro lento construído por um tanque cilíndrico de polipropileno com altura útil de $1000 \mathrm{~mm}$, diâmetro de $580 \mathrm{~mm}$ e seção circular de $0,26 \mathrm{~m}^{2}$. O material filtrante usado foi areia comum utilizada em construção civil e mantas sintéticas não tecidas. $O$ sistema de drenagem foi realizado na parte inferior do filtro e seguia por um tubo externo que estendia até $10 \mathrm{~cm}$ acima da camada de areia, evitando assim a ocorrência de pressão negativa e consequentemente, acúmulo de ar no interior do meio filtrante garantindo a presença 
constante de chorume no interior do filtro. Neste ponto foi também realizada coleta das amostras (Figura 1).

Durante os estudos manteve-se o filtro lento com nível constante mediante utilização de uma bóia hidráulica fixa na parte superior e taxa de filtração constante por meio de registro regulador de vazão na parte inferior (após sistema de drenagem). A taxa adotada foi de $3 \mathrm{~m}^{3} / \mathrm{m}^{2}$ d, sendo monitorada periodicamente através do método volumétrico. $\mathrm{O}$ tempo de detenção hidráulica do chorume foi mantido em 8 horas em média.

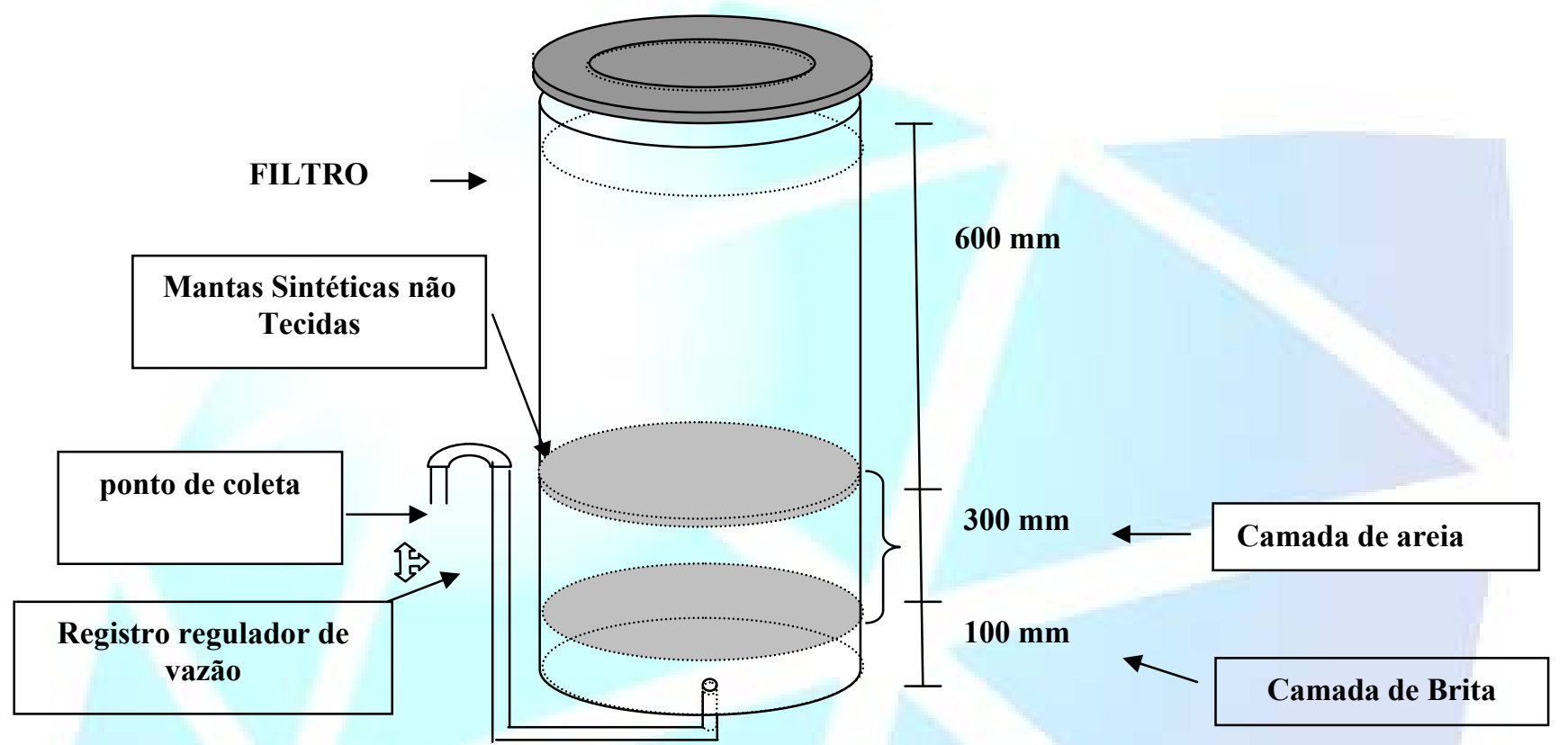

Figura 1. Esquema do filtro lento

\section{Tratamento Fotocatalítico}

O tratamento fotocatalítico foi realizado em um reator de vidro Pyrex com capacidade de 1,7 L (100 mm de diâmetro interno, $145 \mathrm{~mm}$ de diâmetro externo e altura total de $300 \mathrm{~mm}$ ) equipado com sistema de refrigeração à água e recirculação do chorume. Uma representação esquemática do reator pode ser visualizada na Figura 2.

A radiação UV foi provida por uma lâmpada de alta pressão de mercúrio (Philips HPL-N 250 e $400 \mathrm{~W}$ ) com capacidade para emitir comprimentos de onda na região do UV pela remoção do bulbo exterior localizado no centro do reator.

Os experimentos foram processados utilizando refrigeração à água permitindo controlar a temperatura. A agitação do processo foi mantida contínua por meio da recirculação do chorume através de uma bomba hidráulica (Invensys Bav 1115-02U $220 \mathrm{~V} 60 \mathrm{~Hz} 34 \mathrm{~W}$ ). O fornecimento de oxigênio para o processo fotocatalítico foi mantido por borbulhamento de ar através de um vidro sinterizado localizado na parte 
inferior do reator utilizando para isso um compressor com válvula controladora de vazão (Inalar Compact).

A: Câmara Pyrex para reação fotocatalítica

B: Tubo de Quartzo para abrigo da lâmpada UV

C: Câmara para refrigeração a água

D: Vidro sinterizado para formação micro-bolhas de ar

E: Bomba hidráulica para recirculação do percolado

F: Torneira para coleta de amostras

G: Recipiente para retorno de espuma

H: Saída do percolado para

recirculação

I: Entrada do percolado

J: Entrada de água para refrigeração

K: Saída de água de refrigeração

L: Termômetro

M: Bomba de ar

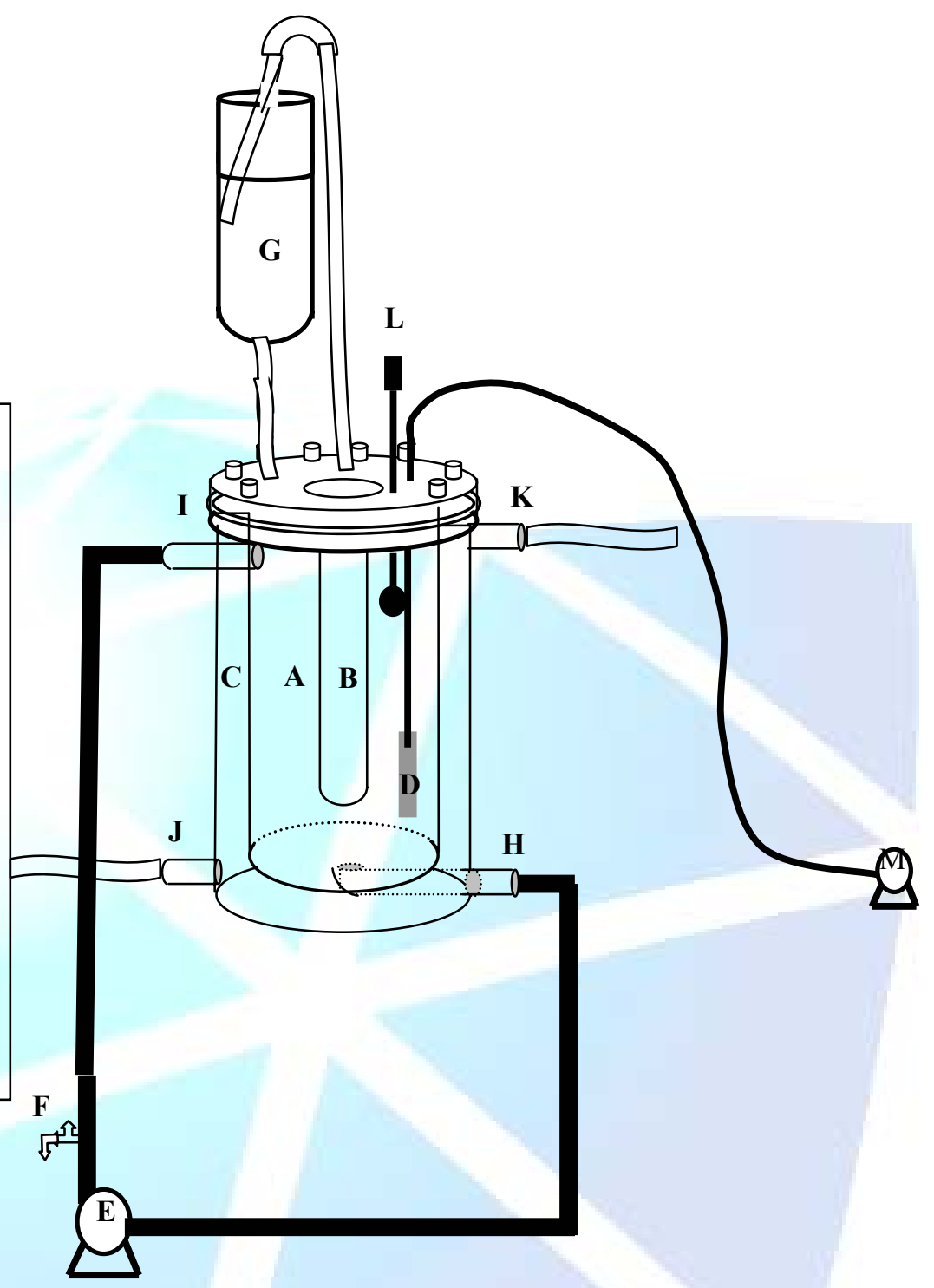

Figura 2. Esquema do reator fotocatalítico.

A massa de $\mathrm{TiO}_{2}$ bem como o chorume a ser tratado foi adicionada na parte superior do reator $(\mathrm{G})$. O dióxido de titânio era misturado por meio da recirculação do chorume. Para o controle analítico, alíquotas foram retiradas em intervalos convenientes e centrifugadas.

Equipamentos e Metodologias Analíticas

O desenvolvimento deste estudo foi realizado a partir de condições otimizadas em estudos preliminares para o tratamento do chorume, onde foi determinado que $\mathrm{o}$ tempo de tratamento da filtração lenta apresentou uma duração de 33 dias sendo que sua eficiência máxima ocorreu no décimo sétimo dia.

$\mathrm{Na}$ otimização da fotocatálise foram encontradas as seguintes condições: concentração de $\mathrm{TiO}_{2}$ de $700 \mathrm{mg} . \mathrm{L}^{-1}$, vazão de ar $15 \mathrm{~L} \cdot \mathrm{min}^{-1}$; temperatura de $45^{\circ} \mathrm{C}$ e 
lâmpada de 400 Watts. Para otimização dos estudos foi utilizada a redução da cor do chorume através da absorvância.

\section{Estudo da Toxicidade Crônica}

Para estudar a toxicidade do chorume foi avaliado o potencial de germinação das sementes de Lactuca sativa L. (alface) Abelmoschus esculentus L. (quiabo), Impatiens balsamina (balsamina) e Celosia cristata (crista-de-galo).

No ensaio de avaliação do potencial de germinação das sementes foi utilizado um método baseado na proposta de INAZAKI et al. (2001), que utilizaram como organismos testes sementes de rúcula (Eruca sativa) e como agente estressor o composto 1,2-diidro-2,2,4-trimetilquinoleina polimerizada presente em efluentes de indústria de produtos químicos.

Neste trabalho foram utilizados conceitos da toxicologia tais como Concentração do Efeito Não Observável (CENO) e Concentração do Efeito Observável (CEO). Os organismos testes utilizados foram sementes de hortaliças: quiabo e alface (adquiridas no Instituto Agronômico de Campinas IAC); e sementes de flores: balsamina e crista-de-galo (adquiridas pela companhia Isla Sementes LTDA). Os ensaios foram realizados empregando uma água de diluição com valor de $\mathrm{pH}$ 7,2, este mantido por um tampão de $\mathrm{KH}_{2} \mathrm{PO}_{4}$ e $\mathrm{K}_{2} \mathrm{HPO}_{4}$ e concentrações otimizadas de nutrientes importantes para estimular a germinação das sementes (Tabela 2). A água de diluição foi usada para preparar diversas concentrações de chorume com o objetivo de verificar apenas a inibição causada pelo chorume (agente estressor).

Tabela 2 - Concentração ótima de nutrientes da água de diluição para realização dos ensaios toxicológicos.

\begin{tabular}{l|c|c|c|c|c|c|c}
\hline $\begin{array}{l}\text { Espécies de } \\
\text { sementes }\end{array}$ & $\begin{array}{c}\mathbf{N} \\
\mathrm{mg} . \mathrm{L}^{-1}\end{array}$ & $\begin{array}{c}\mathbf{P} \\
\mathrm{mg} . \mathrm{L}^{-1}\end{array}$ & $\begin{array}{c}\mathbf{K} \\
\mathrm{mg} . \mathrm{L}^{-1}\end{array}$ & $\begin{array}{c}\mathbf{C a} \\
\mathrm{mg} \cdot \mathrm{L}^{-1}\end{array}$ & $\begin{array}{c}\mathbf{M g} \\
\mathrm{mg} . \mathrm{L}^{-1}\end{array}$ & $\begin{array}{c}\mathbf{Z n} \\
\mathrm{mg} . \mathrm{L}^{-1}\end{array}$ & $\begin{array}{c}\mathbf{C u} \\
\mathrm{mg} . \mathrm{L}^{-1}\end{array}$ \\
\hline $\begin{array}{l}\text { Abelmoschus } \\
\text { esculentus } \boldsymbol{L} \text {. }\end{array}$ & 28,0 & 71,0 & 74,5 & 30,0 & 0,033 & 0,015 & 0,02 \\
\hline Lactuca sativa L. & 35,0 & 41,0 & 61,0 & 30,0 & 0,033 & 0,015 & 0,04 \\
\hline Impatiens balsamina & 35,0 & 41,0 & 61,0 & 30,0 & 0,06 & 0,015 & 0,033 \\
\hline Celosia cristata & 42,0 & 46,0 & 91,5 & 30,0 & 0,06 & 0,015 & 0,033 \\
\hline
\end{tabular}

Os ensaios toxicológicos foram realizados por um período de 120 horas (5 dias), os materiais utilizados foram: sementes, placa de petri, água de diluição otimizada para cada espécie, espátula, lupa, papel toalha e amostra teste.

O método consistiu na disposição de quatro camadas de papel toalha como suporte em placa de petri onde foram colocadas as sementes para desenvolvimento dos estudos (20 sementes), em seguida o suporte foi umedecido com a amostra teste (1,5 mL no primeiro dia e $1,0 \mathrm{~mL}$ nos demais dias), acondicionados em local seco e arejado. Para contraprova do estudo foram preparados frascos contendo sementes 
umedecidas apenas com água de diluição. Os experimentos foram realizados em triplicata e mantidos fechados com tampa da placa de petri.

Ao término dos ensaios foi verificado o CENO e o CEO causado pelas diferentes concentrações da amostra teste em comparação com a contraprova realizado apenas com a água de diluição.

\section{Estudo da Cor do Chorume}

A coloração do chorume foi determinada de acordo com a absorvância no comprimento de onda máximo na região do visível $(400 \mathrm{~nm})$ utilizando espectrofotômetro DR 2000 da HACH.

\section{Estudo do $\mathrm{pH}$}

A determinação dos valores de $\mathrm{pH}$ do chorume foi realizada de acordo com método potenciométrico utilizando medidor de $\mathrm{pH}$ TEC-3M da Tecnal conforme Standard Methods for the Examination of Water and Wastewater, $20^{\text {th }}$ Edition, (APHA, 1998).

\section{Estudo das Concentrações de Nitrogênio}

As análises de nitrogênio amoniacal, nitrito e nitrato foram realizadas de acordo com o método colorimétrico, conforme Standard Methods for the Examination of Water and Wastewater, $20^{\text {th }}$ Edition, (APHA, 1998). O equipamento utilizado foi espectrofotômetro DR 2000 da HACH.

\section{Estudo dos Teores de Fenóis Totais}

As análises de fenóis totais foram realizadas de acordo com o método colorimétrico fundamentada na reação com o reagente de Folin-Ciocalteau, conforme Standard Methods for the Examination of Water and Wastewater, $20^{\text {th }}$ Edition, (APHA, 1998). O equipamento utilizado foi espectrofotômetro DR 2000 da HACH.

\section{Determinação da Matéria Orgânica}

O estudo da concentração da matéria orgânica no chorume foi realizado através da análise de Carbono Orgânico Total (COT) de acordo com a metodologia descrita na norma ISO 8245 (1999), utilizando aparelho TOC 5000 da Shimadzu.

\section{RESULTADOS E DISCUSSÃO}

Os ensaios toxicológicos com sementes para avaliação do tratamento do chorume por filtração lenta e fotocatálise foram verificados por meio do potencial de germinação de algumas sementes mediante avaliação do CENO e o CEO de cada teste. Após tratamento por filtração lenta a porcentagem de diluição que não se observa efeito tóxico (CENO) para as espécies: Abelmoschus esculentus L. (quiabo), Lactuca sativa L.(alface), Impatiens balsamina (balsamina) e Celosia cristata 
(crista-de-galo) sendo de 62, 15, 36 e 30\%, respectivamente. A porcentagem de diluição mínima que se observa efeito tóxico (CEO) foi: 64, 18, 39 e 33\%, respectivamente (Figuras 3 e 4).

Após o tratamento fotocatalítico com $\mathrm{TiO}_{2}$, foi observado CENO de: 94, 27, 50 e 36\% e o CEO de: $96,30,54$ e $40 \%$ respectivamente para as mesmas espécies de sementes supra citadas (Figuras 3 e 4).

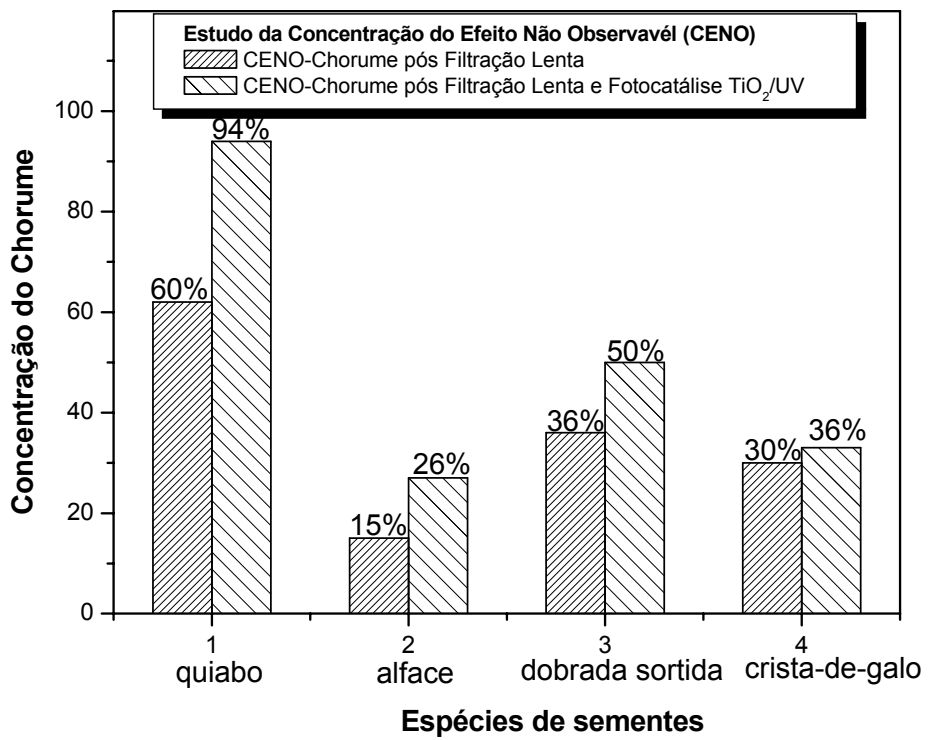

Figura 3. Estudo da concentração do efeito não observável (CENO) utilizando como agente estressor chorume de aterro pós filtração lenta e pós fotocatálise $\mathrm{TiO}_{2}$, para as sementes de Abelmoschus esculentus L. (Quiabo); Lactuca sativa L. (Alface); Impatiens balsamina (dobrada sortida) e Celosia cristata (Crista-de-galo).

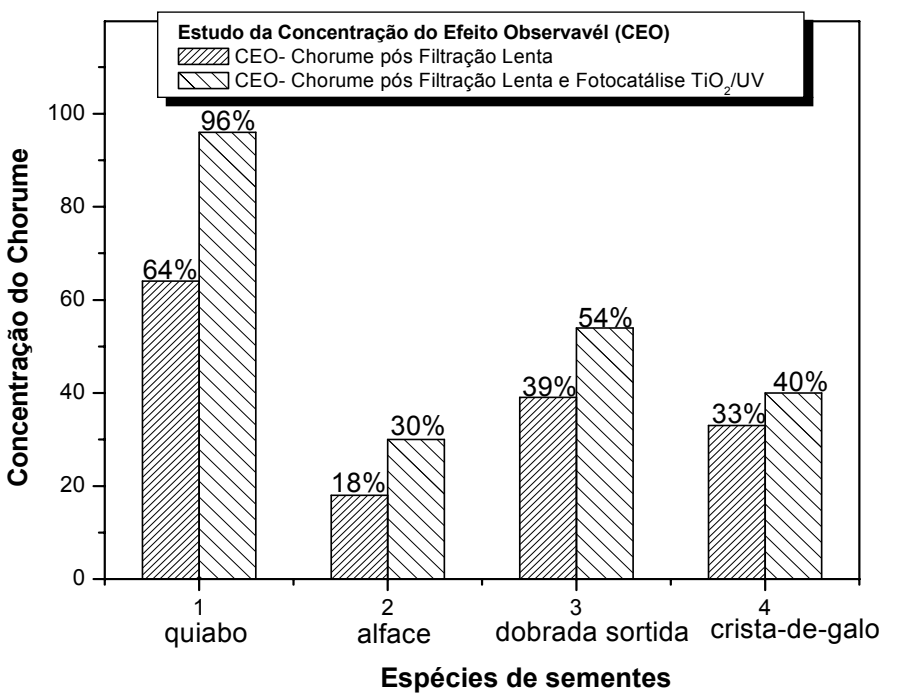

Figura 4. Estudo da concentração do efeito não observável (CEO) utilizando como agente estressor chorume de aterro pós filtração lenta e pós fotocatálise $\mathrm{TiO}_{2}$, para as sementes de Abelmoschus esculentus L. (Quiabo); Lactuca sativa L. (Alface); Impatiens balsamina (dobrada sortida) e Celosia cristata (Crista-de-galo). 
Com os resultados obtidos pôde-se comprovar que o chorume tratado por processo de filtração lenta seguido de fotocatálise heterogênea apresentou melhora significativa para a germinação das espécies Abelmoschus esculentus L. (quiabo) e Impatiens balsamina (balsamina), verificou-se que para o quiabo pode ser utilizado até $94 \%$ de chorume tratado sem causar nenhuma interferência no desenvolvimento germinativo, durante cinco dias. No estudo com a balsamina foram utilizados $50 \%$ de chorume tratado sem observar nenhum efeito inibidor. Estes estudos demonstraram que a metodologia empregada no tratamento do chorume foi importante para redução da toxicidade para espécies estudadas.

Outros parâmetros também importantes para avaliação ambiental foram analisados com a finalidade de verificar a eficiência das metodologias de tratamento do chorume desenvolvida neste estudo. Os principais resultados estão apresentados na Tabela 3.

Tabela 3 - Valores médios dos parâmetros analisados e porcentagem de redução.

\begin{tabular}{|c|c|c|c|c|}
\hline Parâmetros & $\begin{array}{c}\text { Chorume in } \\
\text { natura }\end{array}$ & $\begin{array}{c}\text { Chorume pós } \\
\text { Filtração } \\
\text { Lenta }\end{array}$ & $\begin{array}{l}\text { Chorume pós } \\
\text { Fotocatálise } \\
\text { Heterogênea }\end{array}$ & $\begin{array}{c}\text { \% Redução } \\
\text { Total }\end{array}$ \\
\hline $\mathrm{pH}$ & 8,01 & 8,13 & 9,35 & - \\
\hline Cor (Abs $400 \mathrm{~nm})$ & 2,460 & 1,68 & 0,58 & 76,42 \\
\hline $\begin{array}{c}\text { Nitrogênio } \mathrm{NH}_{4}^{+} \\
\left(\mathrm{mg} . \mathrm{L}^{-1}\right)\end{array}$ & 446,67 & 431,00 & 292,00 & 34,63 \\
\hline $\begin{array}{c}\text { Nitrito } \mathrm{NO}_{2}^{-} \\
\left(\mathrm{mg} \cdot \mathrm{L}^{-1}\right)\end{array}$ & 0,22 & 3,77 & 0,04 & 81,82 \\
\hline $\begin{array}{c}\text { Nitrato } \mathrm{NO}_{3}^{-} \\
\left(\mathrm{mg} \cdot \mathrm{L}^{-1}\right)\end{array}$ & 2,66 & 2,78 & 0,63 & 76,31 \\
\hline TOC $\left(\mathrm{mg} \cdot \mathrm{L}^{-1}\right)$ & 3029,54 & 1703,32 & 973,14 & 67,88 \\
\hline Fenóis $\left(\mathrm{mg} \cdot \mathrm{L}^{-1}\right)$ & 24,09 & 12,77 & 5,51 & 77,13 \\
\hline
\end{tabular}

Com emprego da metodologia de tratamento filtração lenta seguida de fotocatálise foi observada uma elevada eficiência na descoloração do chorume, nas reduções de nitrogênio amoniacal, carbono orgânico total e fenóis totais (Tabela 3).

A intensa coloração do chorume indica a presença de matéria orgânica, que em geral é de difícil degradação, especialmente às substâncias húmicas que são constituídas de macromoléculas como ácidos amorfos, predominantemente aromáticos e hidrofílicos. A cor pode ser altamente interferente aos processos fotossintéticos naturais nos leitos dos rios provocando alterações na biota aquática. Reduções da cor na ordem de $76,42 \%$ são de grande importância ambiental. 
Com relação às reduções das concentrações de nitrogênio amoniacal (34,63\%), também apresentaram resultados relevantes, visto que, a amônia é uma espécie química muito tóxica e geralmente recalcitrante até mesmo para métodos de tratamento mais enérgicos. Segundo Lin e Chang (2000), ao estudar a oxidação de nitrogênio amoniacal por processo eletro-fenton em efluente após pré-tratamento com coagulação química com PAC (polyaluminum chloride), foi necessário empregar elevada concentração de $\mathrm{H}_{2} \mathrm{O}_{2}\left(750 \mathrm{mg} \cdot \mathrm{L}^{-1}\right)$ para conseguir reduções da concentração de amônia em torno de $16 \%$.

As reduções dos valores de nitrito $(81,82 \%)$ e nitrato $(76,31 \%)$ são igualmente importantes, já que, o excesso de nitrogênio em água, na forma de nutriente, pode resultar na eutrofização do meio, provocando aumento de plantas aquáticas que causam interferências e comprometem o corpo de água (CONEGLIAN, 2001).

As reduções da matéria orgânica na ordem de $67,88 \%$, comprovadas pela diminuição do teor de Carbono Orgânico Total (TOC) são resultados altamente significativos em função desse parâmetro, representar a matéria orgânica total presente no chorume. O tratamento empregado neste estudo possui a vantagem de não produzir resíduos para posterior tratamento, além da rapidez do processo de degradação.

No estudo da concentração de fenóis totais foi possível observar 77,13\% de redução da concentração dessa categoria de poluente em 180 minutos de tratamento. Os fenóis presentes no chorume são gerados por meio da degradação de macromoléculas orgânicas em decomposição no aterro sanitário e representam uma classe de compostos altamente recalcitrantes. Os fenóis são espécies químicas altamente polares e sua presença em corpos de água mesmo em concentrações muito pequenas representa um risco à saúde publica.

\section{CONCLUSÕES}

Neste trabalho, foi observado que o emprego da Filtração Lenta seguido de Fotocatálise com $\mathrm{TiO}_{2}$ é uma excelente metodologia de tratamento do chorume podendo alcançar reduções de parâmetros de grande interesse ao meio ambiente e a saúde pública.

O estudo de toxicidade crônica empregando sementes demonstrou que esses organismos testes podem oferecer excelentes bioensaios, já que, quando são rehidratadas elas entram em processo de germinação e sofrem rápidas mudanças fisiológicas tornando-se altamente sensíveis ao estresse ambiental.

Este estudo demonstrou que o emprego de sementes em ensaios toxicológicos pode ser uma excelente alternativa para avaliação de tratamento de águas residuárias, principalmente as que despertam interesse de reuso na agricultura. 


\section{AGRADECIMENTOS}

Os autores agradecem ao Conselho Nacional de Pesquisa Científica - (CNPq) pelas bolsas concedidas e suporte técnico.

\section{REFERÊNCIAS}

ADIN, A. Slow granular filtration for water reuse. Water Science and Technology, v.3, n. 4, p. 123-130, 2003.

ALUKO, O; SRIDHAR, M. Application of constructed wetlands to the treatment of leachates from a municipal solid waste landfill in Ibadan, Nigéria. Journal of Environmental Health, v. 67, n.10, p. 58-62, 2005.

APHA - AMERICAN PUBLIC HEALTH ASSOCIATION- Standard Methods for the Water and Wastewater. 20 ed. New York: APHA, 1998.

BRITO, N.N.; PELEGRINI, R.T.; PATERNIANI, J.E.S. Filtração lenta no tratamento de percolado de aterro sanitário. Revista Minerva, v. 4, n.1, p. 85-93, 2007.

BRITO, N.N. Sistema de Filtração Lenta no Tratamento de Percolado do Aterro Sanitário de Limeira-SP. 2006. 77 f. Dissertação (Mestrado em Engenharia Agrícola) - Faculdade de Engenharia Agrícola, Universidade de Campinas (UNICAMP), Campinas, SP, 2006.

CAMPOS, L.; GRAHAM, N.; SMITH, S. Biomass development in slow sand filters. Water Research. v. 36, p. 4543-4551, 2002.

CELERE, M.; OLIVEIRA, A.; TREVILATO, T.; SEGURA-MUÑOZ, S. Metais presentes no chorume coletado no aterro sanitário de Ribeirão Preto, São Paulo, Brasil, e sua relevância para saúde pública. Cadernos de Saúde Pública, v. 23, n. 4, p. 939-947, 2007.

CHEN, .Y.; LU, C. Characterization of natural organic matters effect on the biodegradation in the slow sand filter. Journal of Environmental Biology, v. 25, n. 4, p. 477-483, 2004.

CONEGLIAN, C.M.R. Diminuição da Concentração de Amônia de Efluente Industrial REPLAN/Petrobrás. 2001.140 f. Tese (Doutorado em Ciências Biológicas) Faculdade de Ciências Biológicas, Universidade Estadual Paulista (UNESP). Rio Claro, SP, 2001. 
DAVE, G.; NILSSON, E. Increased reproductive toxicity of landfill leachate after degradation was caused by nitrite. Aquatic Toxicology, v. 73, n.1, p.11-30, 2005.

DI BERNARDO, L. Métodos e Técnicas de Tratamento de Água, vol 2. Rio de Janeiro: ABES, 1993.

DI BERNARDO, L. Tratamento de Águas de Abastecimento por Filtração em Múltiplas Etapas, vol 1. Rio de Janeiro: ABES/PROSAB, 1999.

INAZAKI, T.; PIÃO, A.; BIDOIA, E.; RÉGIS, G.; ANGELIS, D. F. Testes de toxicidade utilizando Eruca sativa. In: $14^{\text {a }}$ Reunião anual do instituto biológico. Arquivos do Instituto Biológico, v. 68 (supl.), 2001.

INTERNATIONAL STANDARD ORGANIZATION-ISO 8245. Guidelines for the determination of total organic carbon (TOC) and dissolved organic carbon (DOC). 1999.

LIN, S.; CHANG, C. Treatment of landfill leachate by combined electron-fenton oxidation and sequencing bath reactor method. Water Research, v. 34, n. 17, p. 4243-4249, 2000.

MERMILLOD-BLONDIN, F.; MAUCLAIRE, L.; MONTUELLE, B. Use of slow filtration columns to assess oxygen respiration, consumption of dissolved organic carbon, nitrogen transformations, and micorbial parameters in hyporheic sediments. Water Research, v. 39, p. 1687-1698, 2005.

MUHAMMAD, N.; HOOKE, M. Toxicity of heavy metals for microorganisms isolated from slow sand filter schmutzdecke. Environmental Technology, v. 24, n. 9, p. 1097-1102, 2003.

NASSIF, S.; VIEIRA, I.G.; FERNANDES, G. Fatores externos ambientais que influenciam na germinação de sementes. Informativo Sementes do Instituto de Pesquisas e Estudos Florestais. Escola Superior de Agricultura Luís de Queiroz (ESALQ), Universidade de São Paulo (USP), 1998 em www.ipef.br acesso em 0709-2010.

NOGUEIRA, R.; JARDIM, W. Heterogeneous photocatalysis and its environmental application. Química Nova, v 21, n. 1, p. 69-72, 1998.

ZIOLLI, R. L.; JARDIM, W. Mechanism reactions of photodegradation of organic compounds catalyzed by $\mathrm{TiO}_{2}$. Química Nova, v.21, n. 3, p. 319-325, 1998. 